\title{
El gobierno: la fruta prohibida para las mujeres en Marruecos (1997-2021)
}

Government: "The forbidden fruit" for Moroccan Women (1997-2021)

\author{
María Angustias PAREJO-FERNÁNDEZ ${ }^{1}$ \\ Universidad de Granada \\ maparejo@ugr.es \\ https://orcid.org/0000-0003-3958-1124
}

Rajae EL KHAMSI

Universidad Mohammed V de Rabat

ruego2000@yahoo.fr

https://orcid.org/0000-0003-2085-9886

Recibido 11/09/2021. Aceptado 22/11/2021

Para citar este artículo: María Angustias Parejo-Fernández y Rajae EL KHAMSI (2021): “El gobierno: la fruta prohibida para las mujeres en Marruecos (1997-2021)" en Revista de Estudios Internacionales Mediterráneos, 31, pp. 25-48.

Para acceder a este artículo: https://doi.org/10.15366/reim2021.31.002

"Existe una considerable diferencia entre no tener poder y tener un poco de poder, la diferencia entre estar fuera de los focos de decisión y ejecución o ser una parte de ellos. La gente con poco poder puede perder la mayoría de las batallas, sin embargo, participan al menos e imponen ciertas condiciones. $Y$ es en esa etapa decisiva de su historia política en la que se encuentra la mujer marroquí" (Hernes, 1990: 21-22).

\footnotetext{
${ }^{1}$ El presente trabajo se enmarca en el proyecto "Dinámicas y actores transnacionales en Oriente Medio y Norte de África (MENA): Una genealogía de élites y movimientos sociales entre lo local y lo global" (HAR2016-77876-P), cuyos investigadores principales son Laura Feliu y Ferran Izquierdo y ha sido financiado por el Ministerio de Economía y Competitividad, la Agencia Estatal de Investigación (AEI) y el Fondo Europeo de Desarrollo Regional (FEDER).
} 


\title{
Resumen
}

Este artículo analiza la evolución de la participación y la representación política de las mujeres en Marruecos en el Gobierno desde finales de los noventa hasta 2021. Nuestra hipótesis de partida es que el proceso de autonomización del movimiento feminista de los partidos políticos, y su liderazgo y coordinación de la agenda de reivindicación feminista (a finales del siglo XX y tras la Primavera Árabe de 2011) son determinantes en el impulso e implementación de las reformas que favorecen una mayor participación política de las mujeres en Marruecos; pero que esa participación es tardía y limitada en el ámbito del poder ejecutivo.

Palabras clave: mujeres, gobierno, participación política, movimiento feminista, Marruecos

\begin{abstract}
This article analyses the evolution of women's political participation and representation in government in Morocco from the late 1990s to 2021. Our preliminary hypothesis was based on the assumption that the feminist movement's empowerment in the political parties, as well as their leadership and coordination of the agenda of feminist demands (from the end of the $20^{\text {th }}$ century and following the Arab Spring movement of 2011) played a decisive role in the promotion and implementation of reforms favoring a greater inclusion and involvement of Moroccan women in politics; although this participation is long overdue and remains mostly limited in terms of executive power.
\end{abstract}

Keywords: Women, Government, Political participation, Feminist movement, Morocco

\section{Introducción}

El propósito de este artículo es presentar y analizar la evolución de la participación y la representación política de las mujeres en Marruecos en el Gobierno, en la arena nacional, desde finales de los noventa hasta 2021. En los ya nutridos estudios sobre participación y representación política, sigue habiendo una menor atención en la literatura especializada a la participación y representación femenina. Los pioneros trabajos de Moulay Rachid (1985), El Khayat (1992), Akharbach y Rerhaye (1992), Daoud (1993) y Martín (1993) sobre la reducida presencia de las mujeres en los puestos de dirección de los partidos políticos y en el espacio político público, son los cimientos de las publicaciones posteriores de Alami (2002, 2004, 2010, 2014), Bouhssini (s.f.), Dialmy (2008), El Khamsi (2013 y 2017), El Khamsi y Parejo (2017 y 2021), Ennaji y Sadiqi (2011), Enaji et al (2016), Feliu (2004), González Santos (2015), Gribaa (2009), Macías (2005), Parejo (1997, 1999, 2001, 2002), Parejo y El Khamsi (2021), Parejo y Strzelecka (2020 y 2021), Pérez (1991, 1997, 2006, 2007 y 2008), Pérez y Macías (2017 y 2019), Ramírez (2004, 2007 y 2017), Sadiqi (2014 y 2016), Sadiqui y Ennaji, (2006, 2010 y 2011) y Strzelecka y Parejo (2017) sobre la implicación de la mujer en los diversos espacios, procesos e instituciones políticas. Sin embargo, no existe un análisis diacrónico completo sobre la participación política femenina desde la independencia hasta la actualidad en la esfera del ejecutivo nacional. Con este texto queremos contribuir modestamente a paliar esa laguna. 
Nuestros objetivos son: por un lado, indagar la influencia de la acción colectiva y de las estrategias de lucha del movimiento feminista y de mujeres $^{2}$ en la participación y representación política de las mujeres en un régimen híbrido, en las posiciones formales de poder; por otro, explorar y analizar la representación descriptiva de las mujeres en el Gobierno de Marruecos y por último, y conectado con los dos objetivos anteriores, averiguar la incidencia de la ola liberalizadora de la Primavera Árabe en el activismo feminista y en la representación política femenina en el Gobierno.

Desde el punto de vista teórico creemos que la evolución y los graduales cambios del régimen (Feliu y Parejo, 2009 y 2013) tienen mucho que ver con la participación política de las mujeres y que la agencia y la lucha de las mujeres desde finales de los ochenta por dibujar un presente y un futuro más democrático incide en algunos productos de la estructura de poder. La participación y representación femenina en un régimen híbrido (Darhour, 2020; Darhour y Dahlerup, 2013; El Khamsi y Parejo, 2019; Liddell, 2009; Lloren, 2014; Sater, 2007 y 2012; Vairel, 2009) y los enfoques feministas que privilegian la agencia de las mujeres desde reflexiones epistemológicas $y$ experiencias de luchas feministas desarrolladas y teorizadas desde las diversas academias feministas del Norte (Dahlerup, 1986; Hernes, 1990; Mijares, 2017) y del Sur (Hernández, 2008; Hernández y Suárez, 2008; Mahmood, 2008; Mohanty, 2008; Suárez, 2008) serán dos faros teóricos que guiarán nuestro viaje en el tiempo y espacio político de las mujeres marroquíes, en plural, comprendidas como actoras políticas y sujetos de acción política que pueden impulsar cambios.

Nuestra hipótesis de partida, que vertebra este artículo, es que el proceso de autonomización del movimiento feminista de los partidos políticos, y su liderazgo y coordinación de la agenda de reivindicación feminista son determinantes en el impulso e implementación de las reformas que favorecen una mayor participación política de las mujeres en Marruecos. Pero que esa participación es tardía y limitada en el ámbito del poder ejecutivo. El gobierno es la fruta prohibida para las mujeres hasta 1997.

La metodología utilizada para elaborar este trabajo se nutre fundamentalmente de fuentes primarias y también de fuentes secundarias (a través de una revisión y selección de la bibliografía especializada). Hemos decidido unir nuestros recursos y nuestras fuerzas y revisitar nuestros trabajos de campo: El Khamsi (desde 2004-2013 y en la actualidad) y Parejo (1991-1993, 2015 y 2016) para este primer acercamiento a una visión diacrónica de la representación descriptiva de la mujer en el gobierno marroquí desde finales de los noventa a la actualidad. El trabajo de campo desarrollado por Parejo en Marruecos a principios de los noventa se nutre de quince entrevistas en profundidad entre las treinta y tres candidatas a las elecciones de 1993 ( 5 de ellas ostentaban cargos en la estructura orgánica de las direcciones de sus partidos -Organización de la Acción Democrática y Popular, OADP, Partido del Progreso y el Socialismo, PPS y Unión Socialista de Fuerzas Populares, USFP- y también cuatro de ellas eran fundadoras y líderes de diferentes asociaciones como la Asociación Democrática de Mujeres de Marruecos, ADFM, la Unión de Acción Femenina ${ }^{3}$ UAF y la Unión de Mujeres Constitucionales, UFC), dos entrevistas en profundidad con las únicas parlamentarias de 1993 (Partido del Istiqlal, PI y USFP) y numerosas entrevistas entre

\footnotetext{
${ }^{2}$ En este artículo usamos indistintamente movimiento feminista y movimiento de mujeres, en ambos casos nos referimos al movimiento de mujeres organizado desde los años ochenta y cuyas acciones han incidido en las políticas públicas.

${ }^{3}$ La asociación Unión de Acción Femenina pasó a llamarse años más tarde Unión de Acción Feminista.
} 
representantes del mundo académico, personal de la Administración, periodistas representativos de las diversas tendencias políticas y de mercado y miembros de las diversas asociaciones de mujeres. En los más recientes trabajos de campo de 2015 Parejo ocasión de entrevistó en profundidad a cinco parlamentarias elegidas por la circunscripción nacional femenina (dos del PJD, dos de la USFP, y una del PPS) y en 2016, a dos miembros del Consejo Nacional de los Derechos Humanos, un miembro de Attac Maroc y a una de las fundadoras de la UAF y miembro de la Instancia Equidad y Reconciliación (IER). El trabajo de campo desplegado por El Khamsi (desde 2004-2013) aporta diecisiete entrevistas en profundidad: cuatro a presidentas de asociaciones de mujeres, dos de Unión de la Acción Femenina, una de Assaida Al Hurra y una de Solidaridad Femenina; cinco a mujeres políticas (USFP, PJD, PPS, Movimiento Popular, MP, así como la entonces asociación política Fidelidad a la Democracia); tres profesores universitarios de las universidades de Rabat, Tetuán y Fez; cuatro investigadores (una historiadora, un abogado, una antropóloga y una médico que fue miembro de la comisión de reforma de la Mudawana ${ }^{4}$ ); y un ulema, miembro del Consejo de Ulemas.

La información recabada en esos trabajos de campo, en algunas de nuestras investigaciones posteriores (Parejo, 2001 y 2002) y la consulta de diferentes portales web ${ }^{5}$ ha nutrido el desarrollo de la evolución de los movimientos sociales femeninos y sus reivindicaciones y la participación femenina en las arenas electoral, parlamentaria y gubernamental de las que hablamos en las siguientes páginas.

A continuación, presentaremos la denodada lucha de los movimientos de mujeres y de las mujeres marroquíes por sus derechos y el lugar central de las batallas jurídica y de representación política. Seguidamente abordaremos la presencia de las mujeres en el Gobierno desde finales de los noventa hasta la actualidad, un intervalo temporal marcado por dos procesos de liberalización, (principios de los noventa y la segunda década de dos mil, denominado como Primavera Árabe. Para finalizar con unas reflexiones finales a modo de conclusión.

\section{La representación política de las mujeres en el corazón de las batallas del movimiento feminista marroquí}

La emergencia de la conciencia feminista ${ }^{6} y$, posteriormente, del movimiento de mujeres en Marruecos (en los años 80) debe ser analizada teniendo en cuenta dos ámbitos. En primer lugar, el contexto internacional marcado por el interés por la cuestión femenina, a saber, la declaración de la década de las mujeres en 1975, y en segundo lugar, el contexto nacional articulado por el papel desempeñado por las mujeres militantes de los partidos políticos. Como estos últimos relegaban la defensa de los derechos de las mujeres a un segundo plano, las organizaciones de mujeres, desde los años noventa, impulsaron su propio combate dentro y fuera de los partidos por una mayor representación de las mujeres en la escena política a través de numerosas acciones de reivindicación y presión. Una nueva acción colectiva independiente, en cierto modo, de los partidos políticos empezó a gestarse y con ella una nueva identidad colectiva empezó a construirse dando lugar, poco a poco, a un movimiento con nuevos objetivos, nuevos adversarios, y con un objetivo claro, darle a

\footnotetext{
${ }^{4}$ Mudawana significa código y se refiere a la denominación en árabe del Código de Estatuto Personal redactado entre 1957 y 1958 y que fue reformado parcialmente por primera vez en 1993 y luego en 2004 convirtiéndose en Código de la Familia. Abarca todos los textos de ley que rigen la familia (matrimonio, divorcio, custodia, etc.) y la herencia.

5 Como www.maroc.ma, www.hcp.ma, www.adfm.ma, https://maroc-diplomatique.net, https://telquel.ma, https://aujourdhui.ma, https://fr.hespress.com.

${ }^{6}$ Hablamos de emergencia de conciencia feminista y no femenina porque esta etapa ha constituido un salto cualitativo en la organización de las militantes, la definición de sus referencias, objetivos y mecanismos de acción colectiva independiente de los partidos políticos de los que proceden.
} 
M. A. Parejo-Fernández y R. El Khamsi, El gobierno: la fruta prohibida para las mujeres...

la defensa de los derechos de las mujeres la prioridad, los recursos humanos, la ideología y la estructura organizativa que necesitaba.

El florecimiento de la conciencia feminista, que dio lugar a la creación del movimiento, fue, pues, fruto de la decepción de las mujeres que militaban dentro de los partidos políticos, en el marco de lo que se llamaba secciones femeninas. El perfil de estas primeras militantes del movimiento responde a mujeres formadas en el seno del Sindicato de Estudiantes Unión Nacional de Estudiantes de Marruecos (UNEM) y de militantes dentro de partidos de izquierda tales como la Unión Nacional de Fuerzas Populares (UNFP), Unión Socialista de Fuerzas Populares (USFP), Partido del Progreso y del Socialismo (PPS) y de la Organización de Acción Democrática Popular (OADP), entre otros.

La liberación cognitiva de estas mujeres propició el surgimiento de una conciencia feminista y el nacimiento de una nueva subjetividad femenina. Con la toma de conciencia de la especificidad de la cuestión femenina y de la discriminación de las mujeres, se planteó, estratégica e ideológicamente, la necesidad de articular marcos organizativos independientes de los partidos. El periódico 8 de $\operatorname{marzo}^{7}$, de tirada mensual, fue una plataforma de reflexión y debate que más tarde dio paso a un movimiento y al despliegue de diferentes asociaciones de mujeres ${ }^{8}$. Este periódico constituyó el espacio organizativo de acción colectiva y de construcción social del movimiento, de sus referencias teórico-ideológicas y de la nueva identidad. Se convirtió en una herramienta de movilización porque constituía una plataforma abierta de debate, reflexión y demandas. Los partidos políticos, a pesar de sus limitaciones al relegar o no reconocer abiertamente la importancia de la lucha por los derechos de las mujeres, desempeñaron un papel importante en la gestación del movimiento feminista. Constituyeron el caldo de cultivo en el cual fue posible el nacimiento de una nueva conciencia feminista y posibilitaron que de la pugna entre las secciones femeninas y los partidos-madre surgiera la segunda generación de asociaciones feministas (Feliu, 2004: 323).

La gestación de una conciencia feminista y las demandas de una mayor participación política no estuvieron presentes desde los inicios del movimiento. Podemos desglosar unas cuatro etapas del movimiento (El Khamsi, 2013): una primera etapa de gestación, iniciada durante la lucha por la independencia, en la cual aparecen las primeras asociaciones femeninas, influidas por el discurso nacionalista de la época; una segunda que registra la génesis y emergencia de la conciencia feminista en la segunda mitad de los años ochenta y que da lugar al despliegue de la mayoría de las asociaciones de mujeres y feministas; una tercera etapa correspondiente a finales de los años noventa y comienzos de dos mil, marcada por los dos grandes debates alrededor de la Mudawana y el Plan Nacional de Integración de la Mujer en el Desarrollo (PANIFD), en el cual ya se empezó a solicitar la cuota de $33 \%$ para las mujeres en el Parlamento y en las instancias dirigentes de partidos políticos y sindicatos (Alami, 2004) y una cuarta fase de 2011 a la actualidad. Una nueva etapa en la cual las exigencias fundamentales del movimiento feminista son el respeto de los derechos individuales y la aplicación del principio de la paridad en tanto que base constitucional.

\footnotetext{
${ }^{7}$ Véase 8 de marzo, núm. 1, noviembre de 1983; núm. 3, enero de 1984; núm. 4, febrero de 1984; núm. 7, mayo de 1984; y núm. 58, junio de 1992.

${ }^{8}$ Aprovechando la experiencia adquirida a través de la publicación del Periódico 8 de marzo y conscientes de la necesidad de «una organización feminista de masas, democrática e independiente» (lema del periódico 8 de marzo), las militantes de la OADP crean la Unión de la Acción Femenina en 1987. La UAF ve la luz como organización que constituye una nueva corriente de feminismo, arabizada y marcada por las luchas políticas de los años anteriores.
} 
El movimiento feminista en Marruecos (Dialmy, 2008; Feliu, 2004) en sus diferentes etapas de lucha por los derechos de las mujeres ha creado una dinámica continua de formación de coaliciones $y$ redes para presionar, proponer y participar en los procesos de reforma, desempeñando un papel fundamental en el proceso de cambio social y de democratización del país, a través de la articulación de demandas y la exigencia al Estado para que impulse diversas estrategias nacionales (Alami, 2010; El Khamsi, 2013). Este movimiento ha tenido desde sus inicios varios ámbitos de intervención y diferentes acciones de reivindicación: jurídica, social y política. El espacio jurídico es el que más dedicación ha tenido, específicamente la lucha por la reforma del Código de Estatuto Personal (CEP), que constituyó el eje de la acción feminista durante varias décadas desde la famosa campaña de un millón de firmas (Parejo, 2002: 191), que permitió conseguir unas enmiendas superficiales de la Mudawana en 1993, hasta la reforma del Código de la Familia (o Código del Estatuto Personal) de 2004 (Ramírez, 2007). Además del CEP, eje prioritario de la lucha y de la acción colectiva del movimiento, se han ido constituyendo diversas coaliciones, redes y coordinaciones feministas que han luchado por los derechos de las mujeres en las arenas constitucionales, penales o de otros ámbitos legislativos y de regulación. Se puede mencionar, entre otras: la coalición Primavera de la Dignidad, una red fundada en 2010, que aboga por cambiar las leyes discriminatorias, especialmente las relativas a la legislación penal; la coalición Primavera Feminista para la Democracia y la Igualdad, creada en 2011, con el objetivo de participar en el movimiento de reforma constitucional y política que vivió el país tras la Primavera Democrática ${ }^{9}$ (El Khamsi y Parejo, 2021); además del colectivo Parité Maintenant, que se han centrado específicamente en la cuestión de la paridad y la participación política de las mujeres en el poder.

En el espacio político las feministas proponen y reivindican una mejor participación política de las mujeres a través de una mayor representación femenina en los puestos de decisión de los partidos políticos, en los distintos niveles institucionales y fundamentalmente en el Parlamento (Parejo, 1999, 2001 y 2002). Las asociaciones de mujeres desde $1990^{10}$ han iniciado un combate político sobre la cuestión de la representatividad política de las mujeres, movilizando numerosas acciones de reivindicación. Esas acciones parten de que es evidente que no hay democracia efectiva y real, ni desarrollo humano sostenible sin la participación de las mujeres en el proceso de desarrollo (Alami, 2002) y sin la consolidación de su poder, y el reconocimiento de todos los derechos reconocidos universalmente en todos los ámbitos de la vida.

La forma de organización y trabajo consiste en formar comisiones que trabajan en equipo; por un lado, las militantes de las asociaciones de mujeres se organizan en un consejo de coordinación y, por otro, las mujeres políticas forman una comisión de coordinación femenina ${ }^{11}$ de los diferentes partidos (Comité de Coordinación Femenino Democrático, 1997). Se trata de una estrategia de negociación conciliadora donde se apela a todos los actores; el Parlamento, el Gobierno, los partidos, etc. y en la cual se utilizan mecanismos de reflexión, debate, proposición y presión.

Estas estrategias son las que se utilizaron durante los debates sobre la cuota femenina, la lista nacional en las elecciones legislativas, la reforma del Código de los partidos políticos y del Código

\footnotetext{
${ }^{9}$ En Marruecos, los diferentes actores sociales y políticos implicados en los movimientos y movilizaciones populares han preferido hablar de "Primavera Democrática", en lugar de "Primavera Árabe" para incluir a los ciudadanos y colectivos beréberes (Alami, 2014: 66).

${ }^{10}$ La asociación Unión Progresista de las Mujeres Marroquíes (UPFM), creada en 1962, ya planteaba entonces la abolición de todas las formas de discriminación, la igualdad, la democracia y la mejora de las condiciones de trabajo de las mujeres, pero reivindicaciones relativas a la participación política de las mujeres empezaron a constituir el eje principal de las demandas del movimiento feminista en Marruecos en los años 90 junto a la reforma de la Mudawana por parte de la mayoría de las asociaciones de mujeres creadas en los años 80, tales como ADFM, UAF, etc.

${ }^{11}$ En este caso con femenino nos referimos a comisiones de coordinación compuestas de mujeres políticas de diferentes partidos políticos. Estas comisiones se empezaron a reunir para debatir temas como la reforma del código electoral, la cuota, el código de los partidos políticos, etc.
} 
electoral, solicitando que se contemple la perspectiva de género para una mayor capacitación y empoderamiento de las mujeres y una mejor representación femenina en los puestos de decisión. La acción colectiva de la agencia feminista y de los movimientos de mujeres en Marruecos consigue un salto cualitativo cuando sus demandas y propuestas germinan y se aplican medidas de acción positiva correctoras de la desigualdad en las arenas electorales local y nacional. Estas medidas florecen en dos estrategias: pactos políticos entre los partidos y medidas normativas. Los pactos políticos entre partidos se plasman en la cuota de mujeres, articulada en la lista nacional de las elecciones legislativas de 2002 con treinta escaños reservados para las mujeres. En el siguiente proceso electoral de 2007, se produce un estancamiento en la representación femenina. Se mantiene la lista nacional de treinta puestos, pero los partidos incumplen el compromiso adquirido de introducir una cuota de mujeres en las listas locales.

Posteriormente, las medidas normativas han contribuido a una institucionalización que dota de mayor seguridad jurídica los avances en la representación femenina. Las olas de movilizaciones de la Primavera Árabe de 2011 de la mayoría de los países árabes y que coinciden en Marruecos con el llamado Movimiento 20 de febrero, que desembocó en una serie de reformas y medidas, principalmente la nueva Constitución de 2011 y la anticipación de las elecciones legislativas en 2011, sin duda marcan una nueva etapa en las estrategias del movimiento feminista para la reivindicación de mayor representación femenina en las instancias del poder. En 2011 se promulgan dos decretos que modifican la ley que regula la elección de la Cámara de Representantes, uno que establece la lista nacional de mujeres con 60 escaños y el otro que regula la lista nacional de jóvenes con 30 escaños. El Parlamento de 2012 casi duplica el número de mujeres de la etapa legislativa anterior con 67 diputadas, lo que supone un 17\% de una Cámara ampliada. En vísperas de las elecciones de 2016 ve la luz una enmienda de la Ley Orgánica de la Cámara de Representantes por la que se mantiene la lista nacional de mujeres (60 escaños) y la lista nacional de jóvenes se abre a candidatos de ambos sexos (30 escaños). El resultado es un Parlamento con 81 diputadas, un $21,11 \%$ de la Cámara de Representantes. Sin embargo, en el caso del Gobierno, en 2012 la dinámica no ha sido igual. Se abre la legislatura con una sola cartera femenina de ministra, una subrepresentatividad que se corrigió con una remodelación del Gobierno asignando 5 carteras más a mujeres, tras las fuertes movilizaciones de las asociaciones de mujeres. En el siguiente Gobierno de 2017, en el cual mantiene el poder en coalición el partido de Justica y Desarrollo, 8 mujeres consiguen responsabilidades de gobierno, aunque la cifra se reduce a 4 en 2019.

Aunque a nivel del Gobierno no se ha presenciado el mismo cambio cuantitativo que se ha asentado en la Cámara de Representantes después de 2011, gracias a las medidas positivas, con la nueva Constitución de 2011 el movimiento feminista ha podido aprovechar nuevos mecanismos legales que le permiten nuevas formas de movilización y presión. Se trata de la petición "L'effectivité de la parité constitutionnelle à l'horizon 2030", una iniciativa de proposición de ley presentada por el Colectivo Parité Maintenant ante el Parlamento el 31 de diciembre de 2020, y que consiguió recabar 13.000 firmas, más allá de los 5.000 que exige la ley. Basada en la democracia participativa, la iniciativa aspira a alcanzar la paridad constitucional de aquí a 2030. Esta iniciativa pretende aplicar la paridad efectiva en el conjunto de las instituciones del país y en todos los niveles ${ }^{12}$. El presidente

\footnotetext{
${ }^{12}$ Se trata de un proyecto que ya remonta a 2017, y que fue acompañado de varias actividades de debate y reflexión, tales como los encuentros e informes coordinados por la asociación Jossour sobre la elaboración de un dispositivo jurídico para la promoción de la paridad (Véase Bernoussi, s.f.). El Colectivo preparó también y presentó junto a la
} 
de la Cámara de representantes emitió en junio pasado la respuesta de aceptación de la petición en su forma y fondo y de difusión de su contenido ante los grupos parlamentarios.

El 8 de septiembre de 2021 se celebraron por primera vez, simultáneamente, las elecciones legislativas, regionales y comunales. En los comicios a la Cámara de Representantes se sustituye la lista nacional reservada antes a las mujeres por una cuota para asignar 90 escaños a través de 12 circunscripciones regionales. El resultado final ha sido de 96 escaños para mujeres, lo que constituye un $24,3 \%$. En cuanto al Gobierno, se asignaron 7 carteras para mujeres, que se quedaron en 6 , después de la renuncia al cargo por parte de la ministra de la Salud para no compaginarlo con la alcaldía de Casablanca. 5 ministras y una ministra delegada constituyen un porcentaje de $24 \%$ de mujeres en el Gobierno y ocupan por primera vez carteras innovadoras, tales como la transición energética y la transición digital e incluso una cartera reservada históricamente a los hombres como la de economía y finanzas. En cuanto a los porcentajes de representación de mujeres en los consejos comunales es $26,64 \%$ y $36,79 \%$ en los consejos regionales. Con lo cual la representación femenina en el gobierno sólo está a tres décimas respecto de la Cámara de Representantes y por debajo de los Consejos comunales y regionales.

A continuación, plantearemos la problemática de la deficiente representatividad y la restringida participación de las mujeres en la escena política, en concreto en el Gobierno. Abordaremos solo un enfoque de representación descriptiva: nombre y número de mujeres en los distintos gobiernos, cargos que ocupan y formación política a la que pertenecen.

\section{Participación de las mujeres en el gobierno}

Si los escaños del Parlamento tardan tres décadas en acomodar a dos mujeres (1993), el Gobierno es la fruta prohibida que sólo se deja rozar en 1997, con un nombramiento real (Hassan II) de cuatro mujeres como Secretarias de Estado en el Gobierno de Filali (el 24음 gobierno con 28 miembros): Zoulikha Nasiri (Independiente) de Auxilio Nacional; Aziza Bennani (Independiente) de Cultura, Nawal El Moutawakel de Juventud y Deportes y Amina Benkhadra encargada del Desarrollo del Sector Minero, estas dos últimas del RNI (Reunión Nacional de Independientes) (Parejo, 2001: 115). Estos cargos fueron desempeñados sólo hasta marzo de 1998, cuando fueron reemplazadas por ministros hombres en el 250 gobierno. Lo destacable es que, a finales de los noventa, en pleno primer proceso de liberalización política de Marruecos (Parejo, 2010: 365-367), se abre por fin la puerta del Gobierno tímidamente a las mujeres. A grandes rasgos, podemos distinguir un periodo político conservador (desde la independencia a finales de los ochenta) caracterizado por una orientación incipiente y limitada de la "promoción femenina" que margina y elude la problemática de la mujer y otro, marcado por la liberalización política (desde principios de los noventa hasta la actualidad), en la que el régimen moviliza la igualdad de las mujeres como un signo de democratización (Alami, 2010: 16-17) y necesita visibilizar la presencia de la mujer en las esferas legislativa y gubernamental.

Así, en este amplio espacio temporal (desde principios de los noventa a la actualidad) podemos distinguir claramente dos etapas en la evolución de la representación descriptiva de la mujer en el Gobierno. Una primera etapa marcada por el primer proceso de liberalización (1997-2011) y una segunda etapa definida por el segundo proceso de liberalización inaugurado tras la Primavera Árabe

petición un libro blanco en dos tomos sobre la paridad en el ámbito político institucional, el primero, y en el ámbito cultural, social, económico y medioambiental, el segundo. 
(2012-actualidad). La primera etapa se estrena, como hemos visto unas líneas más arriba, con el Gobierno de Filali, al que le sigue el Gobierno de alternancia, presidido por el socialista Abderrahman Yusufi (con 42 personas). En este gabinete sólo se nombraron en 1998 dos mujeres Secretarias de Estado encargadas de la Cooperación y de los Discapacitados, Aïcha Belarbi y Nouzha Chekrouni (ambas de la USFP), y en 2000 se redujo sólo a una mujer (entre las 33 carteras ministeriales). Pero ésta única mujer en el segundo Gobierno de Yusufi de 2000 constituía la primera ministra de la historia de Marruecos ${ }^{13}$. Se trataba de Nouzha Chekrouni y ocupó el cargo de Ministra Delegada encargada de la Condición Femenina, de la Protección de la Familia y de la Infancia y de la Inserción de los Discapacitados ${ }^{14}$. Este ministerio fue suprimido en 2002 en el Gobierno de Jettou y sustituido por otro, en el cual Yasmina Baddou (PI) ocupó el cargo de Secretaria de Estado encargada de la Familia, de la Solidaridad y la Acción Social. Ese cambio, como dice Alami (2004) ha sido considerado como un retroceso en la concepción de la cuestión femenina, y un reflejo de una voluntad de reposicionar a las mujeres en el marco de la familia, después de una larga polémica sobre la cuestión femenina. De hecho, la reforma del CEP que pasa a ser llamado Código de la Familia lo confirman. Además, como se puede apreciar, las funciones ministeriales atribuidas a las mujeres no se alejan de la división clásica de los roles (Hernes, 1990: 85). El Gobierno de Jettou de 2002 (38 miembros) contaba con dos mujeres más, Nouzha Chekrouni (USFP) como Ministra Delegada encargada de la Comunidad Marroquí Residente en el Extranjero y Najima Thay Thay Rhozali (RNI) Secretaria de Estado encargada de la Alfabetización y de la Educación no Formal. Ésta última pierde el cargo en 2004, en el segundo Gobierno de Jettou (35 personas) sustituida por un Secretario de Estado, mientras las otras dos lo mantienen.

El Gobierno de Abbas Al Fassi de 2007 (34 carteras) marca la diferencia en relación con la participación de la mujer en el ejecutivo. Siete carteras fueron confiadas a mujeres, 5 ministras a título pleno: Cultura a Touria Jebrane (Independiente); Desarrollo Social, Familia y Solidaridad a Nouzha Skalli, (PPS); Energía, Minas, Agua y Medioambiente a Amina Benkhadra (RNI); Juventud y Deportes a Nawal El Moutawakel, (RNI) y Salud a Yasmina Baddou (PI). Y dos Secretarias de Estado: Educación a Latifa Labida y Cooperación a Latifa Akherbach (ambas Independientes). En el segundo gabinete de Al Fassi en 2009 (36 miembros) dos de estas mujeres, Touria Jebrane y Nawal El

\footnotetext{
${ }^{13}$ La primera ministra de la historia de España fue Federica Montseny, quien en plena Guerra civil fue Ministra de Sanidad y Salud Pública desde noviembre de 1936 a mayo de 1937. Pasaron 45 años hasta que de nuevo una mujer entró en el ejecutivo. Fue Soledad Becerril, Ministra de Cultura en el último ejecutivo de la UCD (1982). En 1988 González nombró a dos mujeres en su Gobierno: Matilde Fernández en Asuntos Sociales y Rosa Conde como Portavoz del Gobierno. El panorama cambia sustancialmente a mitad de la década de los noventa. El primer Gobierno de Aznar (1996) contó con 4 mujeres y el segundo Gobierno de Aznar (2000) incorporó 5 mujeres a un gabinete de 17 miembros (un 29,4\%) con dos carteras de primer orden, Asuntos Exteriores y Ciencia y Tecnología (Linz et al, 2013: 966-969).

El 17 de abril de 2004 José Luis Rodríguez Zapatero hacía historia al presentar el primer Gobierno con un 50\% de mujeres de la historia de España.

${ }^{14}$ En la única encuesta que conozcamos que se haya realizado en Marruecos (2001), que haya indagado sobre la dimensión cognitiva de la opinión pública sobre el lugar de las mujeres en política, encontramos algunos datos interesantes sobre estos primeros gobiernos con presencia femenina. Un fuerte porcentaje de personas interrogadas, el $76,8 \%$ afirma conocer la representación de mujeres en el Gobierno frente al $21 \%$ que lo ignora, mientras que el $2 \%$ no responde. Entre los que saben de la existencia de mujeres ministras, $50 \%$ conocen los departamentos ministeriales de los que están encargadas las ministras, contra un 44,3 \% que lo ignora. Por lo que respecta a la apreciación de los méritos, la opinión pública entrevistada estima en un $68,2 \%$ que las mujeres ministras merecen ese nivel de responsabilidad y el 17,6\% afirman lo contrario. La parte de mujeres que afirman que las dos mujeres ministras merecen ese nivel de responsabilidad política es ligeramente superior al de los hombres (71,8\% contra 64,6\%) (Alami y Benradi, 2002: 72).
} 
Moutawakil son sustituidas por colegas masculinos al frente de los ministerios de Cultura y Juventud y Deportes. Estas nominaciones reflejan el compromiso político en el proceso de integración de las mujeres en los altos cargos del Estado, no obstante, no dejan de ser insuficientes puesto que están por debajo de las aspiraciones de las militantes feministas, que llevan reivindicando un tercio de la representación para las mujeres desde el famoso debate sobre el PANIFD de 1999.

La segunda etapa de la evolución de la representación descriptiva de la mujer en el Gobierno debuta en 2012, en plena "Primavera Democrática", después de las elecciones anticipadas en 2011, en las cuales por primera vez gana el partido islamista moderado, el Partido de Justicia y Desarrollo (PJD) y forma su gabinete. El primer Gobierno de Benkiran (31 miembros) crea el Ministerio de la Solidaridad, de la Mujer, de la Familia y del Desarrollo Social, recuperando el término mujer en el nombre de la institución, y asignándolo a la única mujer del Gobierno, Bassima Hakkaoui (PJD), la que era, curiosamente, una de las opositoras al PANIFD. Después de la presión y de las demandas de diferentes asociaciones y coaliciones de mujeres, en el segundo Gobierno de Benkiran de 2013, se añade una cartera más de ministra y cuatro ministras delegadas (del total de 39 cargos). El Ministerio de Artesanía, Economía Social y Solidaria recae en Fátima Marouan (RNI) y las cuatro Ministras Delegadas serán: Mbarka Bouaida (RNI) de Asuntos Exteriores y de la Cooperación, Soumia Benkhaldoun, (PJD) de Enseñanza Superior, Hakima El Haite (MP) de Medio Ambiente y Charafat Afilal (PPS) del Agua. En la remodelación ministerial de mayo de 2015 se siguen manteniendo 6 mujeres en el Gobierno (39 personas) y sólo se produce un cambio en la titular del Ministerio Delegado de Enseñanza Superior, Jamila El Moussali (también del PJD como su predecesora).

El Gobierno de 2017, de Saad Eddine El Otmani, cuenta con una más nutrida presencia femenina (8 mujeres de 39 miembros). Una Ministra de la Familia, la Solidaridad, la Igualdad y el Desarrollo Social, manteniendo a Bassima Hakkaoui (PJD) y 7 Secretarias de Estado. Las titulares de estas carteras son: Mounia Boucetta (Independiente) de Asuntos exteriores y Cooperación, Jamila Moussali, (PJD) de Artesanía y Economía Social, Rkia Derham (USFP) de Comercio Exterior, Nezha El Ouafi, (PJD) de Desarrollo Sostenible, Mbarka Bouaida (RNI) de Pesca Marítima, Lamia Boutaleb (RNI) de Turismo y Fatna El Khiyel (MP) de Vivienda.

En la última remodelación del Gobierno de El Otmani (10 octubre de 2019) se reduce la presencia femenina; de 24 miembros del gabinete sólo hay 4 mujeres, si bien aumenta el número de ministras a tres. Nezha Bouchareb (MP) de Ordenación del Territorio Nacional, Urbanismo, Vivienda y Política Urbana; Nadia Fettah Alaoui (Independiente) de Turismo, Artesanía, Transporte Aéreo y de Economía Social y Jamila EL Moussali (PJD) de Solidaridad, Desarrollo Social, Igualdad y Familia. La cuarta cartera es de Nezha El Ouafi (PJD), Ministra Delegada encargada de los Marroquíes Residentes en el Extranjero.

El actual Gobierno de Akhannouch (2021) incrementa la cuota femenina a 6 carteras de un total de 25 miembros. También asciende el número de ministras a cinco. Por primera vez una mujer ostenta la máxima responsabilidad en el Ministerio de Economía y Finanzas, Nadia Fettah Alaoui (RNI); Fatima Ezzahra El Mansouri (PAM) es Ministra de Ordenación del Territorio Nacional, Urbanismo, Vivienda y Política de la Ciudad; Fatim-Zahra Ammor (RNI) es Ministra de Turismo, Artesanía y Economía Social y Solidaria; Leila Benali (PAM) es Ministra de Transición Energética y Desarrollo Sostenible; Aouatif Hayar (PI) es Ministra de Solidaridad, Integración Social y Familia y finalmente la única ministra delegada es Ghita Mezzour (PAM), Ministra Delegada ante el Jefe de Gobierno encargada de la Transición Digital y la Reforma Administrativa.

Como podemos observar en el siguiente cuadro, en la primera etapa de la evolución de la representación descriptiva de la mujer en el Gobierno, marcada por el primer proceso de 
liberalización (1997-2011) si reparamos en los porcentajes de mujeres se dibuja una línea quebrada de trazos irregulares. Partiendo de una bajada considerable de casi 10 enteros del Gobierno Filali $(14,28 \%)$ al primer Gobierno de Yusufi $(4,76 \%)$ se alternan las bajadas y subidas suaves entre los dos Gobiernos de Yusufi (descenso de casi dos enteros, de 4,76\% al 3,03\%) y los dos de Jettou (tras un incremento porcentual de casi cinco enteros en el primer Gobierno de Jettou, el segundo supone un retroceso de poco más de dos enteros, del 7,89\% al 5,51\%). Sin embargo, el primer Gobierno de EI Fassi perfila una línea que se eleva casi 15 enteros, respecto a su predecesor $(20,58 \%$ frente a $5,71 \%)$. El final de esta etapa viene marcado por un nuevo descenso de casi siete enteros en el segundo Gobierno de El Fassi (13,88\%) situándose cuatro décimas por debajo del Gobierno de Filali de comienzos de ese periodo. De los siete gobiernos de esta etapa cuatro de ellos están por debajo del $10 \%$ de presencia femenina (los de Yusufi y Jettou) y dos con porcentajes inferiores al $20 \%$ (el de Filali y el segundo de El Fassi) y otro por encima del 20\% (el primero de El Fassi).

En la segunda etapa definida por el segundo proceso de liberalización inaugurado tras la Primavera Arabe (2012-actualidad) se perfila otra línea quebrada de trazos distintos, pero que se inaugura con una tendencia similar a la etapa anterior, con una bajada de más de 10 enteros entre el último gobierno de El Fassi y el primero de Benkiran (13,88\% y 3,22\% respectivamente). Sin embargo, la presión del movimiento feminista y las diferentes coaliciones de mujeres consiguen que el segundo Gobierno de Benkiran incremente la presencia femenina en un poco más de 12 puntos (15'38\%). El tercer Gobierno de Benkiran se mantiene en ese mismo porcentaje pintando una línea recta horizontal a modo de meseta. El primer Gobierno de El Othmani delinea una línea corta ascendente que supone un ascenso de representación de mujeres de un poco más de 5 puntos $(20,51 \%)$. Esa tendencia ascendente se ve truncada en el segundo Gobierno de El Othmani que dibuja una línea que baja poco más de 4 puntos (16,66\%). Mientras que el actual Gobierno de Akhannouch dibuja un trazo decidido hacia arriba con un incremento de más de siete enteros, situándose hasta ahora a la cabeza de la representación femenina de las dos etapas analizadas (24\%). De los seis gobiernos de esta fase uno está por debajo del $10 \%$ de representación femenina (el primero de Benkiran), tres se sitúan por debajo del $20 \%$ (el segundo y tercer Gobierno de Benkiran y el segundo de El Othmani) y dos superan el $20 \%$ de representación (el primero de El Othmani y el actual de Akhannouch). 
Cuadro 1: Participación de las mujeres marroquíes en el Gobierno (1997-2021)

\begin{tabular}{|c|c|c|c|}
\hline Gobierno & № de mujeres & № de miembros & Porcentaje mujeres \\
\hline 1997 Filali & 4 & 28 & $14,28 \%$ \\
\hline 1998 Yusufi & 2 & 42 & $4,76 \%$ \\
\hline 2000 Yusufi & 1 & 33 & $3,03 \%$ \\
\hline 2002 Jettou & 3 & 38 & $7,89 \%$ \\
\hline 2004 Jettou & 2 & 35 & $5,71 \%$ \\
\hline 2007 El Fassi & 7 & 34 & $20,58 \%$ \\
\hline $\begin{array}{l}2009 \text { El Fassi } \\
\text { (Remodelación) }\end{array}$ & 5 & 36 & $13,88 \%$ \\
\hline 2012 Benkiran & 1 & 31 & $3,22 \%$ \\
\hline 2013 Benkiran & 6 & 39 & $15,38 \%$ \\
\hline $\begin{array}{l}2015 \text { Benkiran } \\
\text { (Remodelación) }\end{array}$ & 6 & 39 & $15,38 \%$ \\
\hline 2017 El Othmani & 8 & 39 & $20,51 \%$ \\
\hline $\begin{array}{l}2019 \text { El Othmani } \\
\text { (Remodelación) }\end{array}$ & 4 & 24 & $16,66 \%$ \\
\hline $\begin{array}{l}2021 \\
\text { Akhannouch }\end{array}$ & 6 & 24 & $24 \%$ \\
\hline
\end{tabular}

Fuente: elaboración propia a partir de El Khamsi (2013), El Messaoudi (2015), Parejo (1999 y 2001), Szmolka (2003 y 2015) y el historial disponible en www.maroc.ma 
M. A. Parejo-Fernández y R. El Khamsi, El gobierno: la fruta prohibida para las mujeres...

Cuadro 2: Cargos y afiliación de las mujeres marroquíes en el Gobierno (1997-2021)

\begin{tabular}{|c|c|}
\hline Gobierno & Cargos y partidos \\
\hline 1997 Filali & $\begin{array}{l}4 \text { Secretarias de Estado: Cultura (Independiente), Juventud y Deportes (RNI), Auxilio Nacional } \\
\text { (Independiente) y Sector Minero (RNI) }\end{array}$ \\
\hline 1998 Yusufi & 2 Secretarias de Estado: Cooperación y Discapacitados (ambas de la USFP) \\
\hline 2000 Yusufi & $\begin{array}{l}1 \text { Ministra de la Condición Femenina, Protección de la Familia, Infancia e Inserción de } \\
\text { Discapacitados (USFP) }\end{array}$ \\
\hline 2002 Jettou & $\begin{array}{l}1 \text { Ministra de MRE (USFP), } 2 \text { Secretarias de Estado: Familia, Solidaridad y Acción Social (PI) y } \\
\text { Alfabetización y Educación No Formal (RNI) }\end{array}$ \\
\hline 2004 Jettou & $\begin{array}{l}1 \text { Ministra de MRE (USFP) y } 1 \text { Secretaria de Estado del Ministerio de Desarrollo Social, de la } \\
\text { Familia y de la Solidaridad (PI) }\end{array}$ \\
\hline 2007 El Fassi & $\begin{array}{l}5 \text { Ministras: Cultura (Independiente); Desarrollo Social, Familia y Solidaridad (PPS); Energía, } \\
\text { Minas, Agua y Medio Ambiente (RNI); Juventud y Deportes (RNI) y Salud (PI) } \\
2 \text { Secretarias de Estado: Enseñanza Escolar y Asuntos Exteriores y Cooperación (ambas } \\
\text { Independientes). }\end{array}$ \\
\hline $\begin{array}{l}2009 \text { El Fassi } \\
\text { (Remodelación) }\end{array}$ & $\begin{array}{l}\text { Se mantienen todas las carteras de } 2007 \text {, salvo las Ministras de Cultura y Juventud y Deportes } \\
\text { que son sustituidas por colegas varones. Quedando en total } 5 \text { carteras ( } 3 \text { Ministras y } 2 \\
\text { Secretarias de Estado. }\end{array}$ \\
\hline 2012 Benkiran & 1 Ministra de Solidaridad, de la Mujer, de la Familia y del Desarrollo Social (PJD) \\
\hline 2013 Benkiran & $\begin{array}{l}2 \text { Ministras y } 4 \text { Ministras Delegadas: } \\
\text { Se mantiene la Ministra de la Solidaridad, de la Mujer, de la Familia y del Desarrollo Social (PJD) } \\
\text { Se nombran otra Ministra de Artesanía, de Economía Social y Solidaria (RNI) y } 4 \text { Ministras } \\
\text { Delegadas: Asuntos Exteriores y Cooperación (RNI); Enseñanza Superior (PJD); Medioambiente } \\
\text { (MP) y Agua (PPS) }\end{array}$ \\
\hline $\begin{array}{l}2015 \text { Benkiran } \\
\text { (Remodelación) }\end{array}$ & $\begin{array}{l}\text { Se mantienen las } 6 \text { carteras. Se cambia la Ministra Delegada ante el Ministerio de Enseñanza } \\
\text { Superior, Investigación y Formación de Cuadros por otra (PJD) }\end{array}$ \\
\hline 2017 El Othmani & $\begin{array}{l}1 \text { Ministra de la Familia, de la Solidaridad, de la Igualdad y del Desarrollo Social (PJD) } \\
7 \text { Secretarias de Estado: Asuntos Exteriores y Cooperación (Independiente); Artesanía y } \\
\text { Economía Social (PJD); Comercio Exterior (USFP); Desarrollo Sostenible (PJD); Pesca Marítima } \\
\text { (RNI); Turismo (RNI) y Vivienda (MP) }\end{array}$ \\
\hline $\begin{array}{l}2019 \text { El Othmani } \\
\text { (Remodelación) }\end{array}$ & $\begin{array}{l}3 \text { Ministras y una Ministra Delegada: } \\
\text { Ministra de Solidaridad, Desarrollo social, Igualdad y Familia (PJD) } \\
\text { Ministra de Turismo, Artesanía, Transporte Aéreo y de Economía social (Independiente) } \\
\text { Ministra de Ordenación del Territorio Nacional, Urbanismo, Vivienda y Política Urbana (MP) } \\
\text { Ministra Delegada encargada de los Marroquíes Residentes en el Extranjero (PJD) }\end{array}$ \\
\hline 2021 Akhannouch & $\begin{array}{l}5 \text { Ministras y una Ministra Delegada: } \\
\text { Ministra de Economía y Finanzas (RNI). } \\
\text { Ministra de Ordenación del territorio Nacional, Urbanismo, Vivienda y Política de la ciudad } \\
\text { (PAM) } \\
\text { Ministra de Turismo, Artesanía y Economía Social y Solidaria (RNI) } \\
\text { Ministra de Transición Energética y Desarrollo Sostenible (PAM) } \\
\text { Ministra de Solidaridad, Integración Social y Familia (PI) } \\
\text { Ministra Delegada ante el Jefe de Gobierno encargada de Transición Digital y Reforma } \\
\text { Administrativa (PAM) }\end{array}$ \\
\hline
\end{tabular}

Fuente: elaboración propia a partir del historial disponible en www.maroc.ma 


\section{Gobiernos con una mayor presencia de mujeres/ministras}

Escribir acerca de la mujer y el poder político en Marruecos es un ejercicio de reflexión sobre la ausencia de poder ${ }^{15}$ y la presencia en posiciones formales de poder. De los treinta y dos gobiernos que se han sucedido en la historia de Marruecos, como hemos detallado antes, sólo trece de ellos han contado con mujeres, desde 1997 al último ejecutivo de 2021. Cincuenta y cinco mujeres han ostentado diferentes responsabilidades ministeriales, treinta y cinco ministras y ministras delegadas y veinte secretarias de Estado. Del corpus total de 443 miembros de esos trece gobiernos, las 55 mujeres representan un $12,41 \%$ de los efectivos ${ }^{16}$. La composición de estos gobiernos oscila entre las 24 carteras del Gobierno de 2019 de El Othmani y las 42 personas del Gobierno de Yusufi de 1998. Si calculamos una media aritmética de la composición de esos trece ejecutivos estaría en 34 miembros. Así que, de esos trece ejecutivos con casi cuatro centenares y medio de personas, las cinco decenas y media de mujeres supondrían un gobierno y medio.

Desgranaremos algunos hitos para interpretar y analizar desde un enfoque de representación descriptiva los datos que poseemos. Los gobiernos con el mayor número de cargos mujeres (ministra, ministra delegada y secretaria de Estado) son por este orden los de El Othmani de 2017 (8), el Fassi de 2007 (7) y los de Benkiran de 2013 y 2015 y Akhannouch de 2021 (6). Si atendemos no solo a los números absolutos, sino también a los porcentajes, el Gobierno de Akhannouch se coloca a la cabeza con un $24 \%{ }^{17}$, seguido de los El Fassi con un $20,58 \%$, siete décimas por encima del Gobierno de Othmani, con un 20,51\%, y lejos del cuarto puesto que ocupa el Gobierno de Benkiran con un $15,38 \%$ de mujeres. Si consideramos los gobiernos con mayor número de ministras

\footnotetext{
${ }^{15}$ Según Hernes (1990:26) "un marco de referencia para el análisis político de la mujer debe considerar no solo el uso legítimo del poder institucional (principal línea de investigación de la Ciencia Política), sino también la ausencia de poder (impotencia), el abuso de poder (uso ilegítimo) y el mal uso del poder (a nivel sistemático y personal) por parte de hombres y mujeres". En este caso y dada la información que manejamos solo atenderemos al binomio ausencia y presencia de la mujer marroquí en una de las instituciones políticas más relevantes, el Gobierno. Aunque tengamos muy presentes, a pesar de los cambios y avances constitucionales de 2011, los límites formales y materiales de poder del Gobierno marroquí (Parejo, 2015).

${ }^{16}$ La presencia de las mujeres en los gobiernos de la democracia en España (1977-2011) es del 18,7\% (Linz et al, 2013: 967)

${ }^{17}$ Ese porcentaje está lejos de la masa crítica (entre el 30 y el 35 por 100) de participación de las mujeres en los gobiernos nórdicos de la que hablaban Dahlerup (1986) y Hernes (1990:32). No obstante, con los datos más recientes del Instituto Europeo para la Igualdad de Género (última actualización de 17-IX-2021) ese 24\% del actual Gobierno de Marruecos, está por encima de los porcentajes de 12 países (Polonia 5\%, Turquía 5,3\%, Rumania y Grecia 9,5 \%, Bulgaria 10,5\%, Eslovenia 11,4 \%, Malta 14\%, Eslovaquia 18,8\%, Hungría, Macedonia del Norte y Bosnia y Herzegovina $20 \%$ y Reino Unido 21,4\%). Sin embargo, estaría por debajo del resto de los países incluidos en la base de datos (26 países). En la franja inmediatamente superior a Marruecos se sitúan: Irlanda 26,6\%, Croacia y Kósovo 27,8\%, Chequia 28,6\%, Luxemburgo 29,4\%, Dinamarca 30\% e Italia y Montenegro 33,3\%. Entre los países que alcanzan la paridad encontramos un primer grupo que se sitúa por debajo del 50\%: Alemania, Portugal y Noruega 40\%, Holanda 43,8\%, Islandia 45,5\%, Serbia $45,8 \%$ y Austria y Lituania $46 \%$. Otro segundo grupo que se posiciona entre el 50 y $60 \%$ : Suecia $50 \%$, Francia $51,2 \%$, Albania 52,9\%, Bélgica 53,3\%, Finlandia 57,9\% y Liechtenstein $60 \%$. Finalmente, por encima del $60 \%$ se coloca a la cabeza España con un 60,9\% (poco más de dos enteros por debajo de la anterior remodelación del Gobierno de Sánchez de julio de 2021 con un 63\%). En el panorama magrebí destacar la casi paridad en el actual gobierno tunecino con un $38,4 \%$ de mujeres, presidido por primera vez en la historia por una Primera Ministra, y la distancia que le separa de los porcentajes de las mujeres en los actuales gobiernos mauritano (17,8\%), libio $(13,8 \%$ ) y argelino $(11,7 \%)$. Instituto Europeo para la Igualdad de Género, https://eige.europa.eu/gender-statistics/dgs/browse/wmidm [consulta: 19 de noviembre de 2021], portales oficiales del gobierno de Túnez, http://fr.tunisie.gov.tn y Argelia, http://www.cg.gov.dz/fr/ y Ficha País de Mauritania 2021, http://www.exteriores.gob.es/documents/fichaspais/mauritania ficha\%20pais.pdf y Ficha País de Libia 2021, http://www.exteriores.gob.es/documents/fichaspais/libia ficha\%20pais.pdf [consulta: 20 de noviembre de 2021].
} 
(en números absolutos) la triada inicial se altera. Los Gobiernos de Benkiran (2013 y 2015) y Akhannouch (2021) pasan del tercer al primer puesto con 6 mujeres ministras, seguidos del Gobierno de El Fassi (2007) con 5 y mientras que el Gobierno de El Othmani baja dos escalones para situarse en tercer lugar con 4 ministras en 2019. En cuanto a los gobiernos con menor representación femenina están los de Yusufi de 2000 y el de Benkiran de 2012 ambos con una sola mujer, aunque esa única ministra represente porcentajes distintos $(3,03 \%$ en el 2 o Gobierno de Yusufi y $3,33 \%$ en el 10 Gobierno de Benkiran). A ellos se les une por la cola, los dos Gobiernos de Jettou, el 2 으 de 2004 con dos mujeres (un 5,71\%) y el 10 de 2002, con tres mujeres (un 7,89\%).

\section{Partidos políticos a los que pertenecen las mujeres con responsabilidades gubernamentales}

Si consideramos los partidos políticos a los que pertenecen estas 55 mujeres que ejercen las diferentes responsabilidades de gobierno (ministras, ministras delegadas y secretarias de Estado) se nos revela está secuencia. El RNI, un partido promonárquico de centro, se sitúa a la cabeza con catorce mujeres; en segundo lugar aparece la formación islamista moderada del PJD (Partido de la Justicia y el Desarrollo) con diez féminas; en tercer puesto figuran las candidaturas independientes con nueve, en cuarto lugar los socialistas de la USFP (Unión Socialista de Fuerzas Populares) con seis mujeres; en quinto lugar los nacionalistas del PI (Partido del Istiqlal) con 5; en sexto lugar dos partidos empatados cuentan cada uno de ellos con cuatro mujeres, los antiguos comunistas del PPS (Partido el Progreso y el Socialismo) y el promonárquico MP (Movimiento Popular) y finalmente en la séptima posición se sitúa el PAM (Partido de la Autenticidad y Modernidad) con tres mujeres. Por bloques, los partidos promonárquicos ${ }^{18}$ (RNI, MP y PAM) suman veintiuna mujeres con diferentes responsabilidades en el Gobierno, un $38,18 \%$ de todos los efectivos femeninos. Las candidaturas independientes aportan nueve mujeres, un 18,36\%. Los partidos de la oposición institucional ${ }^{19}$ (PJD, USFP, PI y PPS) contribuyen a esa visibilización política femenina con veinticinco mujeres, un 45,45\% del corpus de mujeres en esas casi dos décadas y media.

Si prestamos atención sólo a las 35 ministras, el orden de las fuerzas políticas que hemos relatado en el párrafo anterior sufre algunas alteraciones. Hay un baile compartido en el primer puesto con

\footnotetext{
${ }^{18} \mathrm{El}$ análisis del multipartidismo marroquí se ha abordado fundamentalmente desde la posición de los actores políticos respecto al poder central. Así, y subordinando otros tipos de fracturas, el cleavage privilegiado por la literatura especializada, hasta que los partidos de la oposición decidieron entrar en el gobierno en 1998, distinguía entre partidos afines al régimen auspiciados por Palacio (promonárquicos, legitimistas, oficialistas y administrativos) como el RNI, PDN, UC, MP y PAM y partidos que se oponen a la hegemonía política de la monarquía (nacionalistas, democráticos o históricos). Tras la asunción de responsabilidades gubernamentales por la oposición a finales de los noventa, esta pasó a denominarse oposición institucional (Parejo, 2015).

${ }^{19}$ La oposición institucional está formada por los tradicionales partidos de la oposición (PI, USFP, PPS, OADP-PSD y FFD) y el PJD. Son partidos legales que privilegian una estrategia de participación en las arenas electoral, parlamentaria y finalmente gubernamental. Junto a la oposición institucional distinguimos otros dos tipos de oposición: la semiinstitucional, integrada por partidos legales y que seleccionan estratégica e ideológicamente su entrada en el proceso electoral y en el ámbito parlamentario, dependiendo de la coyuntura del momento; y la no institucional, formada por movimientos políticos o sociales y partidos no legales que, por consiguiente, no participan en las arenas electoral, ni parlamentaria, y que rechazan toda colaboración con las instituciones oficiales (Parejo, 2015: 26 y 27).
} 
dos partidos con el mayor número de mujeres ministras. El RNI y el PJD obtienen la medalla de oro con ocho mujeres cada uno. En la medalla de plata del PPS nos sorprende pasando del sexto al segundo puesto con sus cuatro ministras. En el bronce encontramos cuatro formaciones empatadas cada una de ellas con tres ministras (USFP, PI, MP y PAM), desbancando a los independientes que pasan a la última posición con sus dos mujeres. La USFP, el PI, el MP y el PAM mejoran comparativamente sus posiciones y ascienden respectivamente uno, dos, tres y cuatro escalones del podio. Los partidos promonárquicos (RNI, MP y PAM) aportan trece mujeres, un $37,14 \%$ del total de ministras. Las candidaturas independientes sólo cuentan con dos mujeres, un $5,71 \%$. De nuevo los partidos de la oposición institucional (PJD, USFP, PI y PPS) se sitúan a la cabeza con dieciocho mujeres, el $51,42 \%$ de todas las ministras de la historia de Marruecos.

Lo interesante, en este momento, es ver las tendencias de participación de las mujeres ministras en los diferentes gobiernos de coalición desde 2000 hasta la actualidad. Las mujeres del PJD sólo participan en los gobiernos presididos por un primer ministro de su partido: en los Gobiernos de Benkiran (2013 y 2015) y El Otmani (2017 y 2019). Las ministras de la USFP, del PI y del RNI participan en gobiernos presididos por un primer ministro de su partido y en otras coaliciones de gobierno. Las mujeres de la USFP desarrollan sus funciones en el Gobierno de Yusufi (2000) y los presididos por el tecnócrata Jettou (2002 y 2004). Las mujeres del PI, además de participar en los Gobiernos de EI Fassi (2007 y 2009), también forman parte del actual Gobierno de Akhannouch (2021). Las ministras del RNI además de formar parte del Gobierno de Akhannouch (2021) han nutrido los gobiernos presididos por el istiqlalí El Fassi (2007 y 2009) y por el islamista moderado del PJD Benkiran (2013 y 2015). Las mujeres del PPS e Independientes se integran en los gobiernos presididos por el PI y PJD. En concreto, las ministras del PPS alimentan los Gobiernos de El Fassi (2007 y 2009) y de Benkiran (2013 y 2015) y las ministras Independientes forman parte del Gobierno de El Fasi (2007) y de El Othmani (2019). Finalmente, las ministras del MP sólo se integran en gobiernos presididos por un primer ministro islamista: Benkiran (2013 y 2015) y El Othmani (2019).

Cuadro 3: Comparación de la participación de las mujeres marroquíes en el Parlamento y en el Gobierno (1997-2021)

\begin{tabular}{|c|c|c|c|c|c|}
\hline $\begin{array}{l}\text { Elecciones } \\
\text { legislativas }\end{array}$ & $\begin{array}{l}\text { Mujeres en el } \\
\text { Parlamento }\end{array}$ & $\begin{array}{c}\text { Porcentaje } \\
\text { mujeres en el } \\
\text { Parlamento }\end{array}$ & Gobierno & $\begin{array}{c}\text { Mujeres en el } \\
\text { Gobierno }\end{array}$ & $\begin{array}{c}\text { Porcentaje mujeres } \\
\text { en el Gobierno }\end{array}$ \\
\hline \multirow[t]{3}{*}{1997} & 2 & $0,61 \%$ & 1997 Filali & 4 & $14,28 \%$ \\
\hline & & & 1998 Yusufi & 2 & $4,76 \%$ \\
\hline & & & 2000 Yusufi & 1 & $3,03 \%$ \\
\hline \multirow[t]{2}{*}{2002} & 35 & $10,77 \%$ & 2002 Jettou & 3 & $7,89 \%$ \\
\hline & & & 2004 Jettou & 2 & $5,71 \%$ \\
\hline \multirow[t]{2}{*}{2007} & 34 & $10,46 \%$ & 2007 El Fassi & 7 & $20,58 \%$ \\
\hline & & & $\begin{array}{l}2009 \text { El Fassi } \\
\text { (Remodelación) }\end{array}$ & 5 & $13,88 \%$ \\
\hline \multirow[t]{3}{*}{2011} & 67 & $17 \%$ & 2012 Benkiran & 1 & $3,22 \%$ \\
\hline & & & 2013 Benkiran & 6 & $15,38 \%$ \\
\hline & & & $\begin{array}{l}2015 \text { Benkiran } \\
\text { (Remodelación) }\end{array}$ & 6 & $15,38 \%$ \\
\hline \multirow[t]{2}{*}{2016} & 81 & $21,11 \%$ & 2017 El Othmani & 8 & $20,51 \%$ \\
\hline & & & $\begin{array}{l}2019 \text { El Othmani } \\
\text { (Remodelación) }\end{array}$ & 4 & $16,66 \%$ \\
\hline 2021 & 96 & $24,3 \%$ & 2021 Akhannouch & 4 & $24,3 \%$ \\
\hline
\end{tabular}

Fuente: elaboración propia 
M. A. Parejo-Fernández y R. El Khamsi, El gobierno: la fruta prohibida para las mujeres...

En los últimos veinticuatro años (1997-2021) desde que debuta la presencia de la mujer en el Gobierno se han celebrado seis elecciones legislativas (1997, 2002, 2007, 2011, 2016 y 2021) que han dado lugar a seis parlamentos y trece gobiernos presididos por siete primeros ministros, con dos mandatos gubernamentales cada uno. En 1993 por primera vez dos parlamentarias se sientan en la Cámara de Representantes de Marruecos. Esa presencia casi testimonial de sólo dos mujeres en la Cámara Baja se mantiene en 1997, cuando cuatro Secretarias de Estado acceden al Gobierno presidido por Filali (1997). Desde entonces, en este casi cuarto de siglo, si atendemos a los porcentajes más altos de representación femenina en las arenas parlamentaria y gubernamental, el Parlamento de 2021 se sitúa en primera posición con un 24,3\%, seguido del Gobierno de Akhannouch de 2021 con un 24\%. Si comparamos los porcentajes de participación y de representación de las mujeres en los diferentes parlamentos y en los gobiernos que emanan de ese mismo periodo del legislativo reparamos en una serie de gobiernos que están por encima del porcentaje de representación femenina de sus respectivos parlamentos y otros que están por debajo.

Entre los ejecutivos que se sitúan con porcentajes de mujeres superiores al de los parlamentos de su periodo de vida debemos destacar en primer lugar al Gobierno de Filali (1997) con un porcentaje de $14,28 \%$ y 13,67 puntos porcentuales por encima del 0,61\% de representación femenina en el Parlamento de 1997. En segundo lugar, se posiciona el Gobierno El Fassi (2007) con un 20,58\% de mujeres y 10,27 puntos porcentuales por encima del 10,46\% de representación de mujeres en el Parlamento de 2007. En tercer lugar, se coloca el Gobierno de Yusufi (1998) con un tímido 4,76\% de mujeres y 4,15 puntos porcentuales por encima del simbólico 0,61\% de parlamentarias de 1997 . En cuarto lugar, se emplaza el segundo Gobierno de El Fassi (2009) con un 13,88\% de carteras femeninas y 3,42 puntos porcentuales por encima del $10,46 \%$ de diputadas de 2007 . Finalmente, en un cuarto puesto aparece el segundo Gobierno de Yusufi (2000), con la primera ministra de la historia de Marruecos, su emblemático 3,03\% de representación femenina y 2,41 puntos porcentuales por encima del 0,61\% de parlamentarias de 1997.

En los ejecutivos que presentan porcentajes de mujeres inferiores al de los parlamentos de su periodo de vida figuran los Gobiernos del tecnócrata Jettou, los de los islamistas moderados Benkiran y El Othmani y el del liberal Akhannouch. En primer lugar, el primer Gobierno de Benkiran (2012), que florece tras la Primavera Árabe, no visibiliza las demandas de la sociedad civil y con una sola ministra ofrece un escaso $3,22 \%$ de representación femenina ${ }^{20} y-13,78$ puntos porcentuales por debajo del $17 \%$ de diputadas de 2011. Le sigue el segundo Gobierno de Jettou (2004) que acorta las distancias de esta comparación con un saldo negativo, con un $5,71 \%$ de mujeres y $-5,06$ puntos porcentuales por debajo del $10,77 \%$ de parlamentarias de 2002. En tercer lugar, se sitúa el actual Gobierno de El Othmani (2019) con un $16,66 \%$ de ministras y $-4,45$ puntos porcentuales por debajo del $21,11 \%$ de diputadas de 2016. En cuarto lugar, se coloca el primer Gobierno de Jettou (2002) con un 7,89\% de mujeres y $-2,88$ puntos porcentuales por debajo del 10,77\% de diputadas de 2002 . En quinto lugar, el segundo Gobierno y posterior remodelación de Benkiran (2013 y 2015) reducen esa distancia negativa con un $15,38 \%$ de ministras y $-1,62$ puntos porcentuales por debajo del $17 \%$

\footnotetext{
${ }^{20}$ Este descenso de la representación femenina en el primer Gobierno Benkiran, tras los respetables porcentajes de los gobiernos inmediatamente anteriores a la Primavera Árabe de El Fassi (20,58 en 2007 y 13,88 en 2009), nos retrotraen en el tiempo al segundo Gobierno de Yusufi (2000) con una sola ministra y un 3,03\% de representación.
} 
de parlamentarias de 2011. En sexto lugar, el primer Gobierno de El Othmani con su 20,51\% de mujeres casi roza el 21,11\% de diputadas de 2016 con sólo $-0,6$ puntos porcentuales. En séptimo y último lugar el actual Gobierno de Akhannouch que con su $24 \%$ de ministras acorta distancias, situándose sólo tres décimas por debajo del 24,3\% de parlamentarias de 2021.

Este ejercicio de comparación del que no salen muy airosos estos gobiernos, sobre todo los de los primeros ministros islamista, en pleno discurso y narrativa política de la Primavera Árabe y la cuarta ola de transiciones y cambio, se atenúa si consideramos el incremento de la representación parlamentaria tras las cuotas de 2002 y 2004 y la lista de mujeres de 2011 y 2016.

\section{Conclusiones}

Marruecos es un caso interesante para indagar sobre las posibilidades, estrategias, logros y límites de la acción colectiva feminista en un régimen híbrido. La evolución del movimiento feminista desde finales de los noventa ha venido marcada por nuevas estrategias de organización, movilización, reivindicación, propuesta y participación en el proceso de modernización, rebelándose como un componente central de movimiento de derechos humanos, y como un indiscutible actor político que ha ido mejorando con el tiempo y ha ido ganando autonomía, madurez, profesionalización, pluralidad y diversificación. Las mujeres marroquíes y sus asociaciones han sido y son tomadoras y receptoras de políticas, pero desde mediados de los ochenta se organizan para acceder al mercado político de la producción de políticas. Probablemente el papel más importante del movimiento feminista marroquí está en la alteración de la agenda política e introducción del género como "categoría política relevante" (Hernes, 1990: 33), desde finales de los 90 y en su constante reivindicación de una mayor representación de las mujeres en posiciones formales de poder. Reivindicaciones que fructificaron en las medidas de acción positiva en la arena electoral nacional, con los pactos políticos entre partidos, que se plasmaron en la cuota de mujeres de las elecciones legislativas de 2002 y 2007, y las disposiciones normativas, tras la Primavera Democrática, de la lista nacional de mujeres en 2011 y 2016 y las listas regionales de mujeres en 2021.

Por el contrario, en el Gobierno no ha habido medidas de acción positiva (ni pactos políticos entre los partidos, ni institucionalización normativa) que impulsen una mayor representatividad femenina. Por ello la presencia de la mujer es muy volátil dependiendo de la voluntad política y de la coyuntura del momento. En la última fase del primer proceso de liberalización, el primer Gobierno de El Fassi en 2007 ofrece el porcentaje más alto de mujeres con un 20,58\%. Habremos de esperar diez años más tarde, en el segundo proceso de liberalización, tras la Primavera Árabe, para que el primer Gobierno de El Othmani (2017) casi alcance esa proporción femenina con un 20,51\% de mujeres. Sin embargo, el segundo Gobierno de El Othmani (2019) supuso una regresión con un $16,66 \%$ de mujeres. El nuevo Gobierno de Akhannouch (7 de octubre de 2021) corrige esa inflexión negativa a la baja, con un $24 \%$ de representación femenina. Esa cuarta parte de mujeres está todavía muy lejos de la propuesta del Colectivo Parité Maintenant, iniciativa que aspira a alcanzar la paridad constitucional de aquí a 2030.

Finalmente, podemos confirmar y matizar nuestra hipótesis inicial. El proceso de autonomización del movimiento feminista de los partidos políticos, y su liderazgo y coordinación de la agenda de reivindicación feminista han sido determinantes en la alteración de la agenda política e introducción del género como categoría política relevante y en el impulso e implementación de las reformas que favorecen una mayor participación y representatividad política de las mujeres en Marruecos. Pero 
M. A. Parejo-Fernández y R. El Khamsi, El gobierno: la fruta prohibida para las mujeres...

la influencia de la agencia feminista hasta ahora ha sido puntual y limitada en el ámbito del poder ejecutivo.

\section{Bibliografía}

ALAMI, Houria (2002): Genre et politique au Maroc ; les enjeux de l'égalité hommes-femmes entre islamisme et modernisme, Paris, L'Harmattan.

ALAMI, Houria (2004): "Genre et participation politique", en ALAMI, Houria; BENRADI, Malika; CHAKER, Aziz; MOUAQIT, Mohamed; SAADI, Mohamed Saïd y YAAKOUBD, Abdel-llah: Féminin Masculin. La marche vers l'égalité au Maroc. 1993-2003, Rabat, Fundación Friedrich Ebert, pp. 91147.

ALAMI, Houria (2010): Le féminisme d'État au Maroc. Jeux et enjeux politiques, Paris, L'Harmattan. ALAMI, Houria (2014): "Les féminismes marocains contemporains. Pluralité et nouveaux défis", Nouvelles Questions Féministes, no 33/2, pp. 65-79. DOI: 10.3917/nqf.332.0065

ALAMI, Houria y BENRADI, Malika (2002): Les Marocains et les marocaines face au politique. Quelle place pour les femmes, Rabat, Dar al Qalam.

AKHARBACH, Latifa y RERHAYE, Narjis (1992): Femmes et politique, Casablanca, Editions le Fennec.

BERNOUSSI, Nadia (s.f.): Projet de promotion de la représentation politique des femmes au Maroc. Contribution à l'élaboration d'un dispositif juridique pour la promotion de la parité, Fundación Friedrich Ebert Maroc, Asociación Jossour Forum des Femmes Marocaines. www.jossourffmmaroc.com/wp-content/uploads/Contribution-à-l'élaboration-d'un-dispositif-juridique-Fr.pdf [consulta: 16 de julio de 2021].

BOUHSSINI, Latifa (s.f.): "La mujer como actora y como cuestión en el marco del Movimiento 20 de febrero". Texto inédito. المرأة كفاعلة وكقضية في سياق حركة 20 فبراير (Texto inédito facilitado por la autora) COMITÉ de Coordinación Femenino Democrático (1997): “Comunicado de prensa sobre la formación de un marco de coordinación de las organizaciones femeninas", Rabat, Archivo de ADFM. لجنة التنسيق النسائية الديمقراطية، بلاغ صحفي حول تشكيل إطار للتنسيق من طرف تنظيمات نسائية

DAOUD, Zakia (1993): Féminisme et politique au Maghreb, Casablanca, Eddif.

DAHLERUP, Drude (1986): The New Women's Movement: Feminism and Political Power in Europe and the USA, Nueva York, Sage Publications.

DARHOUR, Hanane (2020): Whose empowerment? Gender quota reform mechanisms and dedemocratization in Morocco, Cham, Palgrave Macmillan. DOI: 10.1007/978-3-030-27735-2 11

DARHOUR, Hanane y DAHLERUP, Drude (2013): "Sustainable representation of women through gender quotas: a decade's experience in Morocco", Women's Studies International Forum, no 41, pp. 132-142. DOI: 10.1016/i.wsif.2013.04.008

DIALMY, Abdessamad (2008): Le féminisme au Maroc, Rabat, Les Editions Toubkal.

EL KHAMSI, Rajae (2013): Identidad y género: aproximación al discurso feminista en Marruecos, Tesis Doctoral, Departamento de Sociología y Antropología Social, Institut Universitari d’Estudis de 
la Dona, Universidad de Valencia. https://roderic.uv.es/handle/10550/27422 [consulta: 15 de julio de 2021].

EL KHAMSI, Rajae (2017): “El movimiento feminista marroquí: religión e identidad a debate”, Revista Clepsidra, 2017, no 16, pp. 9-41. https://riull.ull.es/xmlui/handle/915/7054 [consulta: 16 de julio de 2021].

EL KHAMSI, Rajae y PAREJO, María Angustias (2017): Feminismo y compromiso partidista en Marruecos. Las mujeres políticas entre dos fuegos, ponencia presentada al IV Congreso Latinoamericano y Caribeño de Ciencias Sociales, FLACSO, Salamanca, 17-19 de julio.

EL KHAMSI, Rajae y PAREJO, María Angustias (2019): Participación y representación política de las mujeres en Marruecos: de la desigualdad a la acción positiva (1960-2019, ponencia presentada al XXII Encuentro del FIMAM, Institut Europeu de la Mediterrània (IEMed), Barcelona, 24-25 de octubre.

EL KHAMSI, Rajae y PAREJO, María Angustias (2021): "La dinámica del movimiento feminista marroquí tras la Primavera Democrática a partir de dos memorándums", en MACíAS, Juan Antonio (ed.): Dámqrata. Una antología árabe de la democracia en el Norte de África, Granada, Comares (en prensa).

EL KHAYAT, Ghita (1992): Le Maghreb des femmes, Rabat, Eddif.

ENNAJI, Moha y SADIQI, Fatima (eds.) (2011): Gender and Violence in the Middle East, Nueva York, Routledge. DOI: $10.4324 / 9780203830727$

ENNAJI, Moha, SADIQI, Fatima y VINTGES, Karen (2016): Moroccan Feminism, New Perspectives, Trenton, Africa World Press.

EL MESSAOUDI, Amina (2015): Aproximación a los cambios políticos en Marruecos por los márgenes, Rabat, Fundación Konrad Adenauer, en árabe.

FELIU, Laura (2004): El jardín secreto. Los defensores de los derechos humanos en Marruecos, Madrid, La Catarata.

FELIU, Laura y PAREJO, María Angustias (2009): “Marruecos: la reinvención de un sistema autoritario", en IZQUIERDO, Ferran (ed.): Poder y regímenes en el mundo árabe contemporáneo, Barcelona, Bellaterra, Fundación CIDOB, pp. 105-144.

FELIU, Laura y PAREJO, María Angustias (2013): "Morocco: the reinvention of an authoritarian system", en IZQUIERDO, Ferran (ed.): Political Regimes in the Arab World, Oxon y Nueva York, Routledge, pp. 70-99.

GONZÁLEZ SANTOS, María Teresa (2015): “Los movimientos feministas y femeninos en Marruecos y su transposición a la diáspora marroquí en Francia”, Feminismo/s, no 26, pp. 197-219.

GRIBAA, Boutheina (2009): Etat de la situation de la participation de la femme à la vie politique en Algérie, au Maroc et en Tunisie, Santo Domingo y Túnez, L'Institut International de Recherche et de Formation des Nations Unies pour la Promotion de la Femme (UN-INSTRAW) y Centre de la Femme Arabe pour la Formation et la Recherche (CAWTAR). https://www.genreenaction.net/IMG/pdf/publication1.pdf [consulta: 17 de julio de 2021].

HERNÁNDEZ, Rosalva Aída (2008): “Feminismos Poscoloniales: Reflexiones desde América Latina”, en HERNÁNDEZ, Rosalva Aída y SUÁREZ, Liliana (eds.): Descolonizando el feminismo: teorías y prácticas desde los márgenes, Madrid, Catedra, pp. 75-116.

HERNÁNDEZ, Rosalva Aída y SUÁREZ, Liliana (eds.) (2008): Descolonizando el feminismo: teorías y prácticas desde los márgenes, Madrid, Catedra. 
M. A. Parejo-Fernández y R. El Khamsi, El gobierno: la fruta prohibida para las mujeres...

HERNES, Helga María (1990): El poder de las mujeres y el Estado de Bienestar, Vindicación Feminista, Madrid.

LIDDELL, James (2009): "Gender quotas in clientelist systems: the case of Morocco's national list", Al-Raida, no 126-127, pp. 79-86. DOI: 10.32380/alri.v0i0.84

LINZ, Juan J., JEREZ, Miguel y CORZO, Susana (2013): “Ministros y regímenes en España: del sexenio revolucionario a la monarquía parlamentaria", en LINZ, Juan J.: Obras escogidas. Partidos y elites políticas en España, Madrid, CEPC, pp. 917-998.

LLOREN, Anouk (2014): "Gender quotas in Morocco: lessons for women's descriptive and symbolic representation", Representation, no 50, pp. 527 - 538. DOI: 10.1080/00344893.2014.979224

MACÍAS, Juan Antonio (2005): "La mujer en la ideología del movimiento islamista de Marruecos", Miscelánea de Estudios Árabes y Hebraicos. Sección Arabe-Islam, no 54, pp. 101-115.

MAHMOOD, Saba (2008): "Teoría feminista y el agente social dócil: Algunas reflexiones sobre el renacimiento islámico en Egipto", en HERNÁNDEZ, Rosalva Aída y SUÁREZ, Liliana (eds.): Descolonizando el feminismo: teorías y prácticas desde los márgenes, Madrid, Catedra, pp. 165-222.

MARTíN, Gema (1993): “Mujer y vida política magrebí: conflicto entre modernidad y tradición”, en MONTABES, Juan, LOPEZ, Bernabé y del PINO, Domingo (eds.): Explosión demográfica, empleo y trabajadores emigrantes en el Mediterráneo occidental, Granada, Universidad de Granada/AECl, pp. 85-105.

MIJARES, Laura (2017): "Mujeres y revoluciones: la persistencia del paradigma orientalista", en FERREIRO, Juan y RAMOS, Carlos (coords.): La primavera árabe: balance, cinco años después, Barcelona, Atelier, pp. 147-162.

MOHANTY, Chandra Talpade (2008): "Bajo los ojos de Occidente: Academia feminista y discurso colonial", en HERNÁNDEZ, Rosalva Aída y SUÁREZ, Liliana (eds.): Descolonizando el feminismo: teorías y prácticas desde los márgenes, Madrid, Catedra, pp. 117-164.

MOULAY RACHID, Abderrazak (1985): La condition de la femme au Maroc, Rabat, Faculté des Sciences Juridiques, Economiques et Sociales.

PAREJO, María Angustias (1997): Las élites políticas marroquíes: Los parlamentarios (1977-1993), Tesis Doctoral, Facultad de Ciencias Políticas y Sociología, Universidad de Granada.

PAREJO, María Angustias (1999): Las élites políticas marroquíes: Los parlamentarios (1977-1993), Madrid, Agencia Española de Cooperación Internacional.

PAREJO, María Angustias (2001): "Los trabajos y los días de la democracia en femenino en Marruecos", en BIRRIEL, Margarita y RODRÍGUEZ, Pilar (eds.): Mujeres y fortaleza Europa, Granada, Editorial de la Universidad de Granada, pp. 81-117.

PAREJO, María Angustias (2002): "La rebelión de las eternas menores en Marruecos", en GREGORIO Carmen y AGRELA, Belén (eds.): Mujeres de un solo mundo: globalización y multiculturalismo, Granada, Editorial de la Universidad de Granada, pp. 183-209.

PAREJO, María Angustias (2010): "Los sonoros silencios sobre la reforma constitucional en el Marruecos de Mohamed VI", en PAREJO, María Angustias (coord.): Entre el autoritarismo y la democracia. Los procesos electorales en el Magreb, Barcelona, Bellaterra, pp. 365-412. 
PAREJO, María Angustias (2015): “Cambio y límites en Marruecos: propuestas de reforma constitucional sobre el gobierno (2011)", Revista CIDOB d'Afers Internacionals, no 109 (abril), pp. 23-44. https://ddd.uab.cat/pub/artpub/2015/214573/cidob a2015n109p23iSPA.pdf [consulta: 16 de agosto de 2021].

PAREJO, María Angustias y EL KHAMSI, Rajae (2021): “A propósito de la existencia del feminismo de Estado en Marruecos: reflexiones para el debate académico", en MACÍAS, Juan Antonio (ed.), Dámqrata. Una antología árabe de la democracia en el Norte de África, Granada, Comares (en imprenta).

PAREJO, María Angustias y STRZELECKA, Ewa K. (2020): "Processus de réforme constitutionnelle en Méditerranée: explorer les avancés et limites du changement au Maghreb", en GERM (ed.), La Méditerranée plurielle dans un environnement de mondialisation et de déséquilibre régional, Rabat, Editions Bouregreg, pp. 77- 108.

PAREJO, María Angustias y STRZELECKA, Ewa K. (2021): "Las reformas constitucionales de la Primavera Magrebí en Argelia y Marruecos: indicadores privilegiados del alcance del proceso de democratización", en RIBEIRO, Samantha y MOTA, Renata (eds.): A Constituição por elas: a interpretação constitucional sob a ótica das mulheres, Sao Paulo, Quartier Latin (en prensa).

PÉREZ, Carmelo (1991): Panorámica sobre el status social de la mujer magrebí, texto presentado en el curso "Historia, sociedad y cultura en el Magreb", dentro de los III Cursos de verano de Ceuta, 1519 julio.

PÉREZ, Carmelo (1997): “Mujeres árabes en el espacio público: indicadores, problemas y perspectivas", en DEL AMO, Mercedes (ed.): El imaginario, la referencia y la diferencia: siete estudios sobre la mujer árabe, Granada, Departamento de Estudios Semíticos, pp. 90-102.

PÉREZ, Carmelo (2006): "Mujeres marroquíes ante la reforma de la Mudawwana: cambio social y referente cultural", en PEREZ, Carmelo (ed.): Sociedad civil, derechos humanos y democracia en Marruecos, Granada, Universidad de Granada, pp. 295-332.

PÉREZ, Carmelo (2007): “Mujeres y ciudadanía en el Magreb hacia una nueva realidad social en los albores del siglo XXI", Anales de Historia Contemporánea, no 23, pp. 119-146 https://digitum.um.es/digitum/bitstream/10201/11882/1/2319884.pdf [consulta: 16 de julio de 2021].

PÉREZ, Carmelo (2008): “Mujeres marroquíes en la vida pública: entre el cambio social y la identidad musulmana", en LÓPEZ, María Dolores (ed.): España y Marruecos: mujeres en el espacio público, Sevilla, Alfar-Ixbilia, pp. 89-110.

PÉREZ, Carmelo y MACÍAS, Juan Antonio (2017): "La construcción histórica de la hegemonía ideológica del PJD en Marruecos: La marcha islámica de 2000 y el debate sobre las mujeres", Revista de Estudios Internacionales Mediterráneos, no 22, pp. 1-34. DOI: 10.15366/reim2017.22.001

PÉREZ, Carmelo y MACÍAS, Juan Antonio (2019): “Ideología, acción y reacción: la marcha islámica de Casablanca del 12 de marzo de 2000" en FELIU, Laura, MATEO, Josep Lluís e IZQUIERDO, Ferran (eds.), Un siglo de movilización social en Marruecos, Barcelona, Bellaterra, pp. 343-362. https://dialnet.unirioja.es/servlet/articulo?codigo=7856252 [consulta: 16 de julio de 2021].

RAMÍREZ, Ángeles (2004): “Oriente es Oriente? Feminismo e islamismo en Marruecos", Revista Internacional de Sociología, no 39, pp. 9-33. DOI: 10.3989/ris.2004.i39.247

RAMÍREZ, Ángeles (2007): "Paradoxes et consensus: le long processus de changement de la Moudawwana au Maroc", L'Année du Maghreb, no II, pp. 23-34. DOI: 10.4000/anneemaghreb.76 
M. A. Parejo-Fernández y R. El Khamsi, El gobierno: la fruta prohibida para las mujeres...

RAMÍREZ, Ángeles (2017): "Las otras Soulaliyates: tierra y movilizaciones legítimas e ilegítimas en Marruecos", Revista de Estudios Internacionales Mediterráneos, no 23, pp. 15-28. DOI: 10.15366/reim2017.23.002

SADIQI, Fatima (2014): Moroccan Feminist Discourses, Nueva York, Palgrave Macmillan. DOI: $\underline{10.1057 / 9781137455093}$

SADIQI, Fatima (ed.) (2016): Women's Movements in the Post-“Arab Spring" North Africa, Nueva York, Palgrave Macmillan. DOI: 10.1057/978-1-137-50675-7

SADIQUI, Fatima y ENNAJI, Moha (2006): "The Feminization of Public Space: Women's Activism, the Family Law, and Social Change in Morocco", Journal of Middle East Women's Studies, no 2 (2), pp. 86-114. DOI: 10.2979/MEW.2006.2.2.86

SADIQUI, Fatima y ENNAJI, Moha (eds.) (2010): Women in the Middle East and North Africa. Agents of change, Londres, Routledge.

SADIQUI, Fatima y ENNAJI, Moha (eds.) (2011): Gender and Violence in the Middle East, Londres, Routledge.

SATER, James N. (2007): "Changing politics from below? Women parliamentarians in Morocco", Democratization, vol. 14, no 4, pp. 723-742. DOI: 10.1080/13510340701398352

SATER, James N. (2012): "Reserved Seats, Patriarchy, and Patronage in Morocco", en FRANCESCHET, Susan, KROOK, Mona Lena y PISCOPO, Jennifer M. (eds.): The Impact of Gender Quotas, Oxford, Oxford University Press, pp. 72-86. DOI: 10.1093/acprof:oso/9780199830091.001.0001

STRZELECKA, Ewa K. y PAREJO, María Angustias (2017): "Constitutional reforms processes", en SZMOLKA, Inmaculada (ed.): Political Change in Middle East and North Africa: After the Arab Spring, Edinburgh, Edinburgh University Press, pp. 115-142. DOI: 10.3366/edinburgh/9781474415286.003.0006

SUÁREZ, Liliana (2008): “Colonialismo, gobernabilidad y feminismos poscoloniales”, en HERNÁNDEZ, Rosalva Aída y SUÁREZ, Liliana (eds.): Descolonizando el feminismo: teorías y prácticas desde los márgenes, Catedra, Madrid, pp. 31-74.

SZMOLKA, Inmaculada (2003): Actores y proceso político en Marruecos: Dinámicas internas y sus percepciones en la prensa española, Tesis Doctoral, Departamento de Ciencia Política y de la Administración de la Universidad de Granada.

SZMOLKA, Inmaculada (2015): "Inter- and intra-party relations in the formation of the Benkirane coalition governments in Morocco", The Journal of North African Studies, vol. 20, no 4, pp. 654-674. DOI: $10.1080 / 13629387.2015 .1057816$

VAIREL, Frédéric (2009): “La «liste nationale»: un quota électoral pour quoi faire?”, en ZAKI, Lamia (dir.): Terrains de campagne au Maroc. Les élections législatives de 2007, Paris, Karthala, pp. 113157.

\section{Portales web consultados}

https://aujourdhui.ma/ [consulta: 10 de noviembre de 2021]

https://eige.europa.eu/ [consulta: 19 de noviembre de 2021]

https://fr.hespress.com [consulta: 10 de noviembre de 2021] 
http://fr.tunisie.gov.tn [consulta: 20 de noviembre de 2021]

https://maroc-diplomatique.net [consulta: 10 de noviembre de 2021]

https://telquel.ma [consulta: 10 de noviembre de 2021]

http://www.cg.gov.dz/fr/ [consulta: 20 de noviembre de 2021]

http://www.exteriores.gob.es/portal/es/saladeprensa/paginas/fichaspais.aspx [consulta: 20 de noviembre de 2021]

www.adfm.ma [consulta: 18 de noviembre de 2021]

www.hcp.ma [consulta: 10 de noviembre de 2021]

www.maroc.ma [consulta: 8 de enero de 2021] 